Kansas State University Libraries

New Prairie Press

\title{
STATISTICAL ISSUES IN STUDIES OF THERMOREGULATION IN FARM ANIMALS
}
A. M. Parkhurst
G. L. Hahn

Follow this and additional works at: https://newprairiepress.org/agstatconference

Part of the Agriculture Commons, and the Applied Statistics Commons

\section{(c) (1) $\Theta($}

This work is licensed under a Creative Commons Attribution-Noncommercial-No Derivative Works 4.0 License.

\section{Recommended Citation}

Parkhurst, A. M. and Hahn, G. L. (1989). "STATISTICAL ISSUES IN STUDIES OF THERMOREGULATION IN FARM ANIMALS," Conference on Applied Statistics in Agriculture. https://doi.org/10.4148/ 2475-7772.1449

This is brought to you for free and open access by the Conferences at New Prairie Press. It has been accepted for inclusion in Conference on Applied Statistics in Agriculture by an authorized administrator of New Prairie Press. For more information, please contact cads@k-state.edu. 


\title{
STATISTICAL ISSUES IN STUDIES OF THERMOREGULATION IN FARM ANIMALS
}

\author{
A. M. Parkhurst and G. L. Hahn
}

University of Nebraska-Iincoln

and

U. S. Meat Animal Research Center, ARS-USDA, Clay Center, NE

\section{Abstract}

Patterns of tympanic temperature response were identified in ad-lib-fed cattle exposed to constant or cyclic $( \pm 7 \mathrm{C})$ conditions at two levels of air temperature: $10 \mathrm{C}$ and $28 \mathrm{C}$. Use of time series analysis following the DDS approach of Pandit and $W u$ indicate the thermoregulatory control dynamics for steers at $28 \pm 7$ C were markedly different from those at the other conditions. Preliminary evaluations using the ideas of chaos and non-linear dynamics show promise of further characterization of stress responses in farm animals.

Reywords: circadian rhythms, tympanic temperatures, data dependent systems, time series, entrainment, chaos theory, non-linear dynamics, thermal stress

\section{Background of Biological Investigation}

The capability of farm animals to maintain homeothermy through thermoregulation is central to coping with thermal stressors through behavioral or physiological responses. Typical behavioral responses include seeking a more favorable microclimate if available (e.g., shelter from wind or precipitation in cold, or shade from sun and increased utilization of water in hot environments), and altering posture and contacts with other animals to change exposed surface area. Decreased feed intake lowers metabolic heat production and therefore decreases the amount of heat dissipation required in hot weather, while increased feed intake in cold conditions leads to higher metabolic rates. Physiological responses include adjustment of metabolic levels necessary to sustain body processes, vasodilation and increased respiration to increase heat dissipation, or vasoconstriction to conserve body heat. Minimizing the overall impact of thermal stressors is essential to satisfactory performance, health and welfare of farm animals. Variations are common among species and individuals in their ability to adjust to thermal challenges. Disruptions of normal body temperature and thermoregulatory processes can be important criteria for assessing the ability of farm animals to cope with thermal stressors.

Thermoregulatory control is a complex process linked primarily to the hypothalamus in the brain. In thermoregulatory studies of animals, body temperature, along with other physiological, environmental and behavioral variables, is observed at regular time intervals. Such time series usually exhibit cyclic fluctuations which are thought by many investigators to be circadian in nature (Aschoff, 1983; Stanier et al., 1984; Hahn, 1988). While much remains to be learned about thermoregulatory control systems in mammals (Cossins and Bowler, 1987), recent evidence indicates an innate monophasic body temperature rhythm in ad-lib-fed animals in the absence of stressors (Hahn, 1988). These innate rhythms, with maxima in late evening and minima in mid-morning, can be altered by environmental stressors (e.g., adverse air temperature, weather events, or transport). Shifts in the mean, amplitude and phase of the circadian body temperature rhythms occur when thermal thresholds characteristic of species and individual animals are exceeded. 
Resultant rhythms may closely follow air temperature cycles, basically becoming entrained but with a time lag. Shifts in body temperature rhythms immediately after exposure to adverse environments are often more marked than those measured after prolonged exposure (Hahn, 1988). Acute responses and acclimation to chronic exposure to environmental stressors also may be influenced by the type of digestive process in the animal (i.e., monogastric or ruminant).

A series of experiments have been conducted at the U.S. Meat Animal Research Center (MARC) to evaluate shifts in circadian body temperature rhythms and the underlying thermoregulatory responses of Bos taurus growing feeder cattle $(250-500 \mathrm{~kg}$ body weight) to known thermal stressors. Typically, cattle have a relatively constant body temperature over a wide variety of environments (Finch, 1986), but with a monophasic rhythm of 0.5 to $1.2 \mathrm{C}$ in moderate thermal conditions, whether in drylot or controlledenvironment facilities (Hahn et. al., 1986). Tympanic temperatures have been recorded in the MARC studies to represent body temperature rhythms in response to stressing and nonstressing thermal environments.

This paper describes the statistical issues involved in evaluation of tympanic temperature measurements from initial experiments, discussed in the context of specific selected treatments. Emphasis is on time-series and system analysis techniques that appear to serve well for analyzing both the altered rhythms and the thermoregulatory responses (Parkhurst and Hahn, 1987; Hahn, Parkhurst and Nienaber, 1987).

\section{Background of Statistical Evaluation}

The goal was to construct differential equations from the data. Lowdimensional models of dynamics have commonly been used to represent more complex dissipative behavior (Arrowsmith and Place, 1982; Priestley, 1988). Ultimately, it may be possible to identify output from well-known secondorder nonlinear oscillators such as Duffing or Rayleigh-Van der Pol equations which have been used to model the human circadian system (Strogatz 1987). Meanwhile, the focus is on using linear differential equations to model the system.

One approach is to use Pandit and Wu's data dependent systems (DDS) analysis which focuses on the dynamic aspects of ARMA models as characterized by Green's function or the autocovariance function. An initial assumption is that the data come from a stable stationary stochastic system. Hence, the dynamics of the system may be represented in the form of a linear combination of characteristic roots. Using Green's function as an example,

$$
G_{k}=g_{1} \lambda_{1}{ }^{k}+g_{2} \lambda_{2}{ }^{k}+\ldots+g_{m} \lambda^{k}
$$

where $\lambda_{i}$ 's are the characteristic roots of an $n^{-t h}$ order linear difference equation (Pandit and $\mathrm{Wu}, 1983$ ). Alternatively, linear combinations of exponential functions of these roots give rise to $n^{\text {th }}$ order differential equations.

The dynamics of the system may then be characterized in terms of the characteristic roots or eigenvalues. When the roots are real and positive, the instantaneous rate of heat dissipation above the core (baseline) temperature can be represented by exponential decay or "lagged memory" that begins with an increase, then decays exponentially to zero. Pulses may be represented by negative real roots. Such pulses exhibit properties of a feedback control system such as an on-off thermostat, as indicated by cossins and Bowler, (1987). Our conjecture is the thermostat may turn on when the temperature reaches the body core temperature and turn off when a thermal threshold is encountered. With a pair of complex conjugate roots, the model 
may reflect sinusoidal dynamics with different degrees of damping. Real roots with absolute value close to one can represent constant trend of growth or decay while complex roots close to $|1|$ may represent circadian rhythms with the period given by the imaginary part.

\section{Description of Pilot Controlled-Environment Study}

Measurements: Tympanic temperatures were recorded hourly by a datalogger from thermocouple sensors inserted into the ear canal of each steer, using techniques previously described (Wiersma and Stott, 1973; Scott et al., 1973). The overall system was carefully calibrated, with obtained accuracy limits of $.05 \mathrm{C}$ or better. Considerable effort was required to maintain functioning sensors because of breakage, disconnected or chewed leads, and the need to alternate sensors from ear to ear at no more than weekly intervals to minimize ear canal irritation. However, the technique does provide an acceptable index of hypothalamic temperature (Benzinger, 1959, 1964; Guidry and McDowel1, 1965; Weirsma and Stott, 1974), which serves as the principal integrator from which animals adjust heat production, loss or retention to maintain thermoregulatory control by animals (Stanier et al., 1984).

Treatments: The treatment design was a $2 \times 2$ factorial consisting of two factors: regime and temperature. The two temperature levels selected represented non-stressing (thermoneutral, $10 \mathrm{C}$ ) and potentially stressing (hot, 28 C) conditions, based on prior reports on the effects of temperature on cattle performance and physiological response (c.f., NRC, 1981). Regime levels selected were cyclic and constant temperatures. Cyclic conditions sinusoidally varied $\pm 7 \mathrm{C}$ about either of the mean temperature levels, to approximate naturally-varying spring/fall (thermoneutral) or summer (hot) conditions. Constant conditions represent a contrasting environment often used in environmental research as a basis for comparison.

Experiment: In this study, four animals were housed in pairs and each pair received two treatments. All four animals began the study at the nonstressing temperature. Two of the steers were placed in the constant temperature regime; the other two, in the cyclic regime. Steers were kept in a thermoneutral environment for two weeks, with tympanic temperatures recorded the last eight days. The steers were then subjected to heat stress and the experiment continued for six days.

During the experiment, the steers were maintained in individual stalls in controlled-environment chambers at MARC with a photoperiod of $14 \mathrm{~h}$ light and 10h dark. They were ad-lib-fed a high-energy pelleted ration, supplemented with $1 \mathrm{~kg}$ hay/day to maintain rumen function.

\section{Statistical Analysis}

The analysis focuses on identifying patterns of response over time. Results are used to support assumptions proposed in the literature as reviewed above and/or to generate new constructs or models for thermoregulatory systems.

Visual inspection of the time series data indicates a dynamic process (Figure 1 ) and because of the suspected heterogeneity among animals, data from each steer were analyzed separately. Individual analyses were also made for each treatment, since the parameters of interest were more likely to remain constant within rather than between the treatment segments. In addition, a $24 \mathrm{~h}$ washout period was imposed between the thermoneutral and thermal stress conditions, with measurements at the beginning of the thermal stress conditions omitted from the analyses in an attempt to eliminate 
possible transitory effects of start-up conditions.

DDS analysis was used to estimate the order of the time series. The $(2 n, 2 n-1)$ strategy indicated the dimensions ranged from a low order ARMA $(1,1)$ to a high-order ARMA $(6,5)$, Table 1 .

At this point, the interest lies not so much in the order of the models, but rather in the characteristic roots which may identify a stationary process. Under thermal stress, one might expect roots close to $|1|$. Such roots could verify a trend illustrating acclimation to an environmental stressor. The biorhythm would be brought back into phase with the innate rhythm. No such characteristic roots were detected. However, examination of the individual models did reveal pairs of complex conjugate roots close to $|1|$, Table 2 .

Using a period of $24 \mathrm{~h}$, it is then possible to estimate the amplitude and phase angle via autoregression, Table 3. This approach leads to useful results by differentiating among thermal treatments. Basically, the hot cyciic treatment appears to represent envirommental impacts on the physiological process. The innate biorhythm appears to be entrained by an envirommental stressor. It is also possible to estimate the parameters for each animal, as well as to compare the parameters for the animals with the chamber information to estimate the time it takes for the cyclic heat stress to become entrained.

After the deterministic function is removed, the dynamics of the system can be interpreted from Green's function. For the hot cyclic treatment (Steer 219), the composite Green's function (Figure 2) shows the vibrations as a damped sinusoidal wave. Additional information can be obtained from the individual components of Green's function. The relative importance of each component is indicated by the percent variation. The variance for the thermal stress condition is predominantly (78\%) influenced by a damped sinusoidal function that requires approximately $48 \mathrm{~h}$ to die out. This result may illustrate acclimation to the thermal stressor and suggests the biorhythm may take 2 days to be brought back into phase with the innate rhythm. The secondary (228) sinusoidal function of period 2.5 may be the result of a feedback control system such as a thermostat.

The DDS analysis of cyclic thermal stress provides insight into the thermoregulatory process and substantiates the ideas proposed in the Iiterature discussed above. Analysis of the other treatments, was not as revealing as that of the hot cyclic condition. Consider the constant thermoneutral condition, Figure 1. Is the signal to noise ratio too large to detect periodicity? The DDS procedure indicates the most parsimonious model is approximately a random walk, Table 1. But that is counterintuitive. Perhaps the problem is the linearity constraints on the model. Suppose the thermoneutral state is chaotic or quasi-periodic; how does one begin the search for chaos?

A simple approach which fits well with time series analysis is to study the phase portrait. The axes of the phase space are signal versus velocity or momentum, $i . e$. the signal, $x(t)$ vs. it's first derivative. In the univariate case, the behavior of the derivative should be related to a lag, $x(t+l)$ where $l$ is the time delay. The choice of 1 ag does not appear to be critical provided it is not a natural period of the process (Moon, 1987). Phase diagrams are studied to determine the attractor. (Attractors are states of dynamic motion.) The phase diagram for cyclic thermal stress suggests the attractor is a closed curve, which is associated with a periodic motion or limit cycle, (Figure 3b). This could happen when the hot cyclic temperature is imposed on the animal's biorhythm. When the frequency of the stressor is 
close to the limit cycle of the internal biorhythm, the resulting periodic motion can become entrained at the stressor frequency. Thus, the conclusion of a sinusoidal function of period 24 for thermal stress treatment is reaffirmed.

The phase diagrams for the other treatments suggest a different story. The attractor for the cyclic thermoneutral condition appears almost periodic or quasiperiodic, (Figure $3 a$ ). This could happen because the periodic force of the treatment is too small to become entrained and what is displayed is a combination of oscillators. For constant thermal stress, the attractor may be periodic, but, it is difficult to tell because the process rises to a threshold and then decreases, (Figure 3d).

The most complex condition is the constant thermoneutral state, (Figure 3c). This process may also be quasiperiodic. It could be dominated by a combination of oscillators and the attractor could become strange suggesting a chaotic process.

The above observations are also supported by the use of the Fourier spectrum (Figure 4). In each case, the peak at approximately $24 \mathrm{~h}$ indicates a diurnal cycle. However, the multiharmonics in the neutral conditions suggest that is far from the whole story. These phenomena require further study and may be addressed by Poincaré maps, surfaces in a three dimensional phase space or other tools used to identify routes to chaos (Bergé et al., 1984; Moon, 1987).

\section{Issues Generated by the Statistical Analysis}

The DDS approach involves a sequence of $F$ tests, multiple t-tests, and tests for autocorrelation as statistical issues in estimating dimensionality. There are also issues of size of sampling intervals, length of series, magnitude of signal-to-noise ratio and statistical graphics needed to detect and illustrate treatment differences.

There are questions about the robustness of the DDS procedure in modeling data with deterministic periodicity and trends. The concept of stochastic periodicity (Box and Jenkins, 1976) needs to be re-examined especially in light of chaos. And, since the characteristic roots are useful not only in detecting periodicity and trends, but also in interpreting Green's function, attention needs to be given to more conditional tests for eigenvalues.

However, the most intriguing statistical issues raised in this paper are generated by consideration of chaos, the study of non-linear dynamic systems. Some rudimentary questions are: When is a system linear or nonlinear? Is the ability to differentiate among attractors dependent on the signal to noise ratio? Is it possible to distinguish among periodic, aperiodic or quasi-periodic, chaotic, and random events, especially in the presence of self-excited vibrations? Physicists, engineers and mathematicians are developing new ways to describe the dynamics of nonlinear systems. Statisticians need to respond with equally inventive ways of estimating those ever changing parameters (Priestley, 1988; Tong, 1983).

\section{Further Considerations}

It may be fruitful to conceptualize thermoregulation in terms of nonlinear oscillators, such as those used in modeling human responses as mentioned above (Strogatz 1987) and in Glass and Mackey (1988). The primary oscillator(s) represents the animal's own biorhythm. In the thermoneutral zone, it is a self-excited function. It is not constrained by an external driving force. However, as the ambient temperature is increased, so is the amplitude of the external driving force(s) - the secondary 
oscillator(s). Thus, the impact of the forcing function itself is dynamic over time as the animal behaviorally and physiologically copes with thermal stress. Eventually, a thermal threshold is reached. In this situation, the impact of the external function becomes dominant and the second oscillator drives the system. Control passes from the internal self-excited oscillator to the external driving force.

These new conjectures need further evaluation by techniques which go beyond those discussed in this paper. The theory of chaos, bifurcation or fractal analysis, and generally the study of non-linear dynamics (Bergé et al., 1984; Hayashi, 1964; Moon, 1987; Thompson and Stewart, 1986), have an apparent potential for such evaluations to further delineate thermoregulatory control processes and responses of farm animals to stressors. 
TABLES

TABLE 1. Dimension of ARMA Model for each Treatment

CYCLIC

CONSTANT

\begin{tabular}{cr}
\multicolumn{2}{c}{ Sample 1} \\
NEUTRAL \\
$\begin{array}{cr}(4,3) & (3,1) \\
(1,1) & (2,0)\end{array}$
\end{tabular}

Sample 2

NEUTRAI STRESS

$(6,5)$

$(2,1)$

$(2,0)$

$(3,1)$

TABLE 2. Periods Indicated by Conjugate Roots of Length one

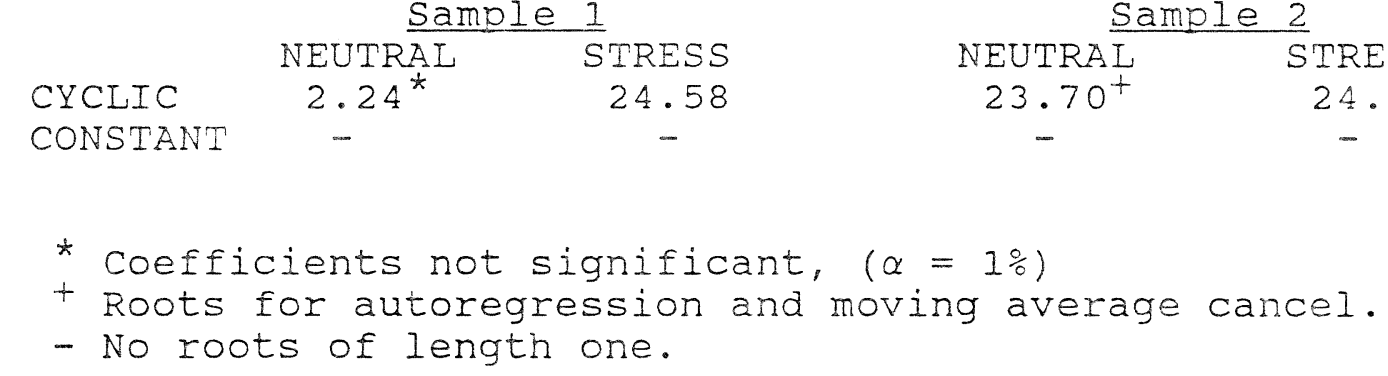

TABLE 3. Parameters of Stationary Process Temperature $\frac{\text { Tympanic }}{\text { Sample } 1}$ Sample $2 \quad$ Chamber
MEAN ( $\left.{ }^{\circ} \mathrm{C}\right)$
40.15
AMPLITUDE
0.97
40.25
0.87
28.56
PHASE ANGLE (rad.) 2.44
2.48
6.37
PHASE SHIFT (rad.) -1.17
1.13
0.60 


\section{REFERENCES}

Arrowsmith, D. K. and C. M. Place. 1982. Ordinary Differential Equations: A Qualitative Approach with Applications. Chapman \& Hill, London/New York.

Aschoff, J. 1983. "Circadian control of body temperature: A review". J. Therm. Biology 8:143-147.

Benzinger, T. H. 1959. "On physical heat regulation and the sense of temperature in man". Proc. Nat'1. Acad. Sci. 45:645-657.

Benzinger, T. H. 1964. "The thermal homeostasis of man". Sympos. Soc. Experimental Biology 18:49-61.

Bergé, Pierre, Yves Pomeau and C. Vidal. 1984. Order Within Chaos: Towards a Deterministic Approach to Turbulence. John Wiley \& Sons, New York.

Box, G. E. P. and G. M. Jenkins. 1976. Time Series Analysis: Forecasting and Control. Holden-Day, San Francisco.

Cossins, A. R. and K. Bowler. 1987. Temperature Biology of Animals. Chapman \& Hall, London/New York.

Finch, V. A. 1986. "Body temperature in beef cattle: It's control and relevance for production in the tropics". J.Ani. Sci. 62:531-542.

Glass, L. and M. C. Mackey. 1988. From Clocks to Chaos: The Rhythms of Life. Princeton University Press. Princeton, New Jersey.

Guidry, A. J. and R. E. McDowel1. 1965. "Tympanic membrane temperature for indicating rapid changes in body temperature". J. Dairy Sci. 49(1):74-77.

Hahn, G. I. 1988. "Body temperature rhythms in farm animals - a review \& reassessment relative to envirommental influences". Biometeorology (in press).

Hahn, G.L., J. A. Nienaber, H. G. Klemcke, and G. L. Gose. 1986. "Body temperature fluctuations in meat animals". Amer. Soc. Agric. Engrs. St. Joseph, MO. Paper 86-4009.

Hahn, G.L., A. M. Parkhurst, and J.A. Nienaber. 1987. "Tympanic temperature rhythms in cattle in selected environments". Proc. 8th Conf. on Biometeorology \& Aerobiology. American Meteorological Society, Boston, MA. Rept. B/A 4.4:320-323.

Hayashi, C. 1964. Nonlinear Oscillations in Physical Systems. Princeton University Press, Princeton, New Jersey.

Moon, F. C. 1987. Chaotic Vibrations: An Introduction for Applied Scientists and Engineers. John Wiley \& Sons, New York.

NCR. 1981. "Effect of environment on nutrient requirements of domestic animals". Nat'l. Research Council. Nat'l. Academy Press, Washington, D.C. 
Pandit, S. M. and S. M. Wu. 1983. Time Series and System Analysis with Applications. John Wiley \& Sons, New York.

Parkhurst, A. M. and G. L. Hahn. 1987. "Data dependent systems time series analysis of cattle tympanic temperature rhythms". Amer. Soc. Agric. Engrs. St. Joseph, MO. Paper MCR 87-131.

Priestley, M. B. 1988. Non-linear and Non-stationary Time Series Analysis. Academic Press, San Diego, CA 92101.

SAS Institute Inc. 1984. SAS/ETS User's Guide. Version 5 Edition. SAS Institute Inc., Cary, NC.

Scott, I. M., H. D. Johnson, and G. L. Hahn. 1983. "Effect of programmed diurnal temperature cycles on plasma thyroxine level, body temperature and feed intake of Holstein dairy cows". Int'1 J. Biometeorology 7(1):47-62.

Stanier, M. W., L. E. Mount, and J. Bligh. 1984. Energy Balance and Temperature Regulation. Cambridge Univ. Press, Cambridge.

Strogatz, S. H. 1987. "A comparative analysis of models of the human sleepwake cycle". Lectures on Mathematics in the Life Sciences. American Mathematical Society. Providence 19:1-38.

Thompson, J. M. T., and H. B. Stewart. 1986. Nonlinear Dynamics and Chaos: Geometrical Methods for Engineers and Scientists. John Wiley \& Sons, New York.

Tong, H. 1983. "Threshold models in non-linear time series analysis". Lecture Notes in Statistics Vol. 21. Springer-Verlag, New York.

Wiersma, F. and G. H. Stott. 1974. "Dairy cow body temperatures in a hot climate". Trans. ASAE 17:745-747.

Wiersma, F. and G. H. Stott. 1983. "A technique for securing a temperature probe adjacent to the tympanic membrane in bovine". Trans. ASAE 26(1):185187. 


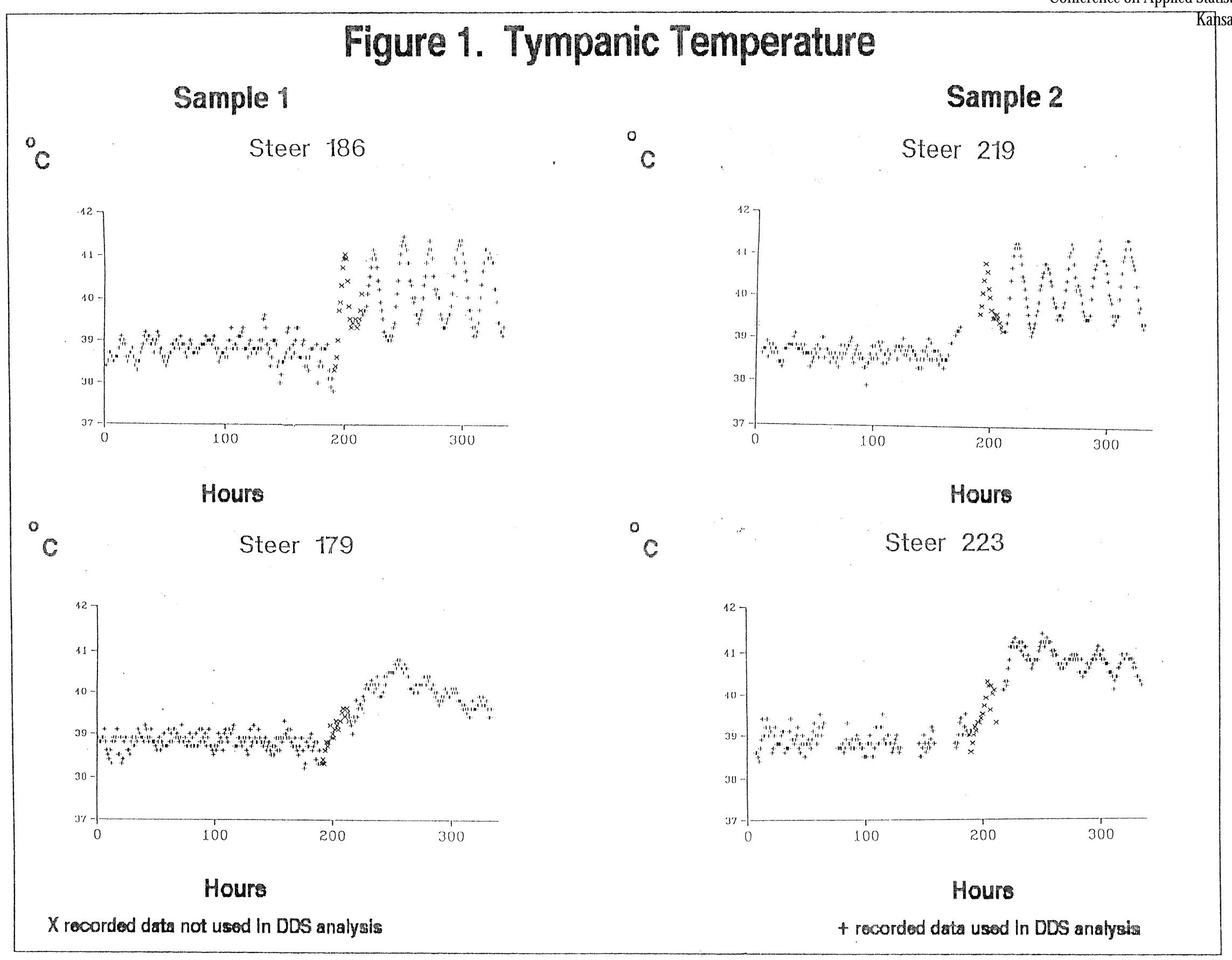




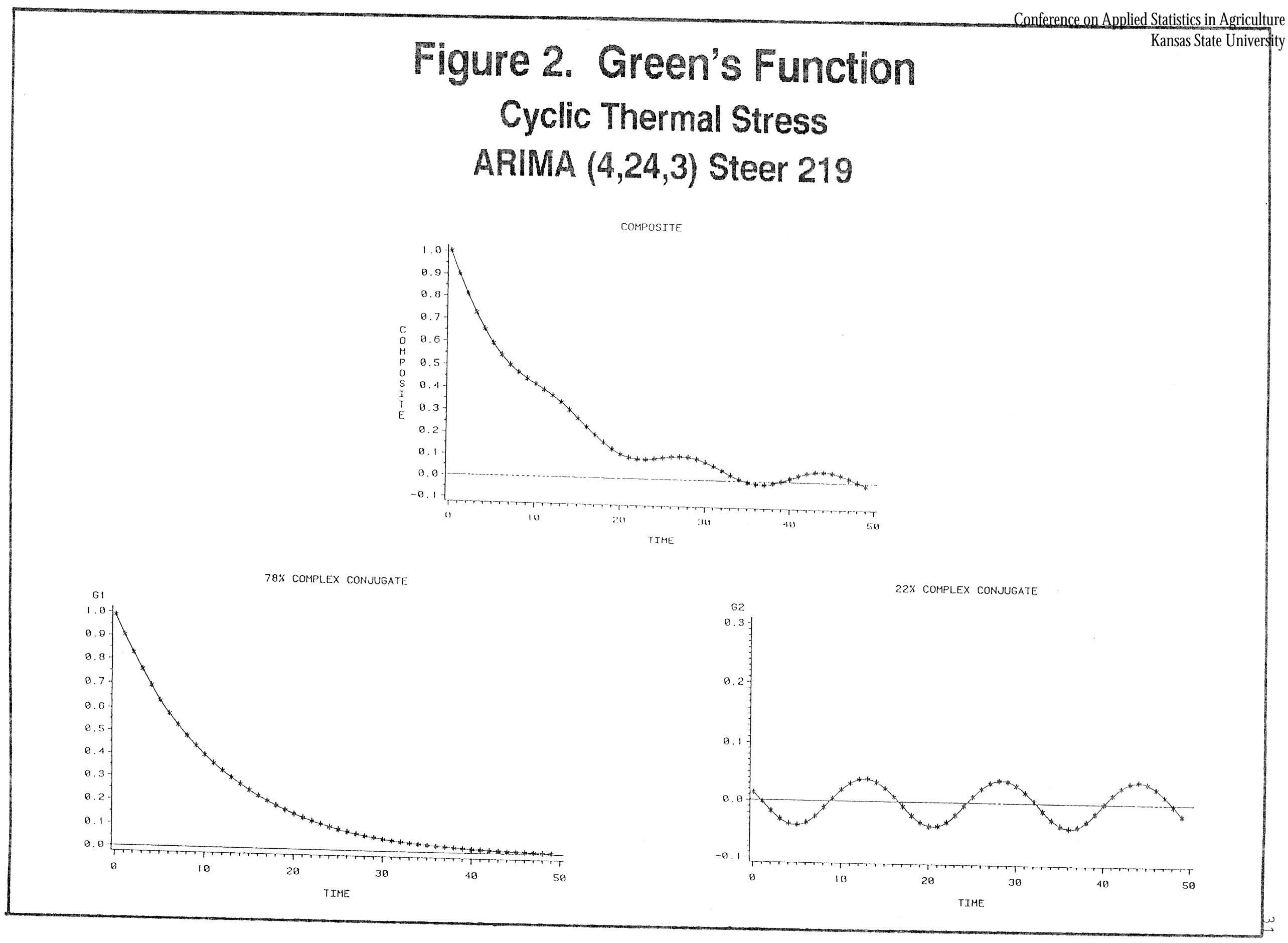




\section{Figure 3. Phase Diagrams for Tympanic Temperature}

CYCLIC THERMONEUTRAI,
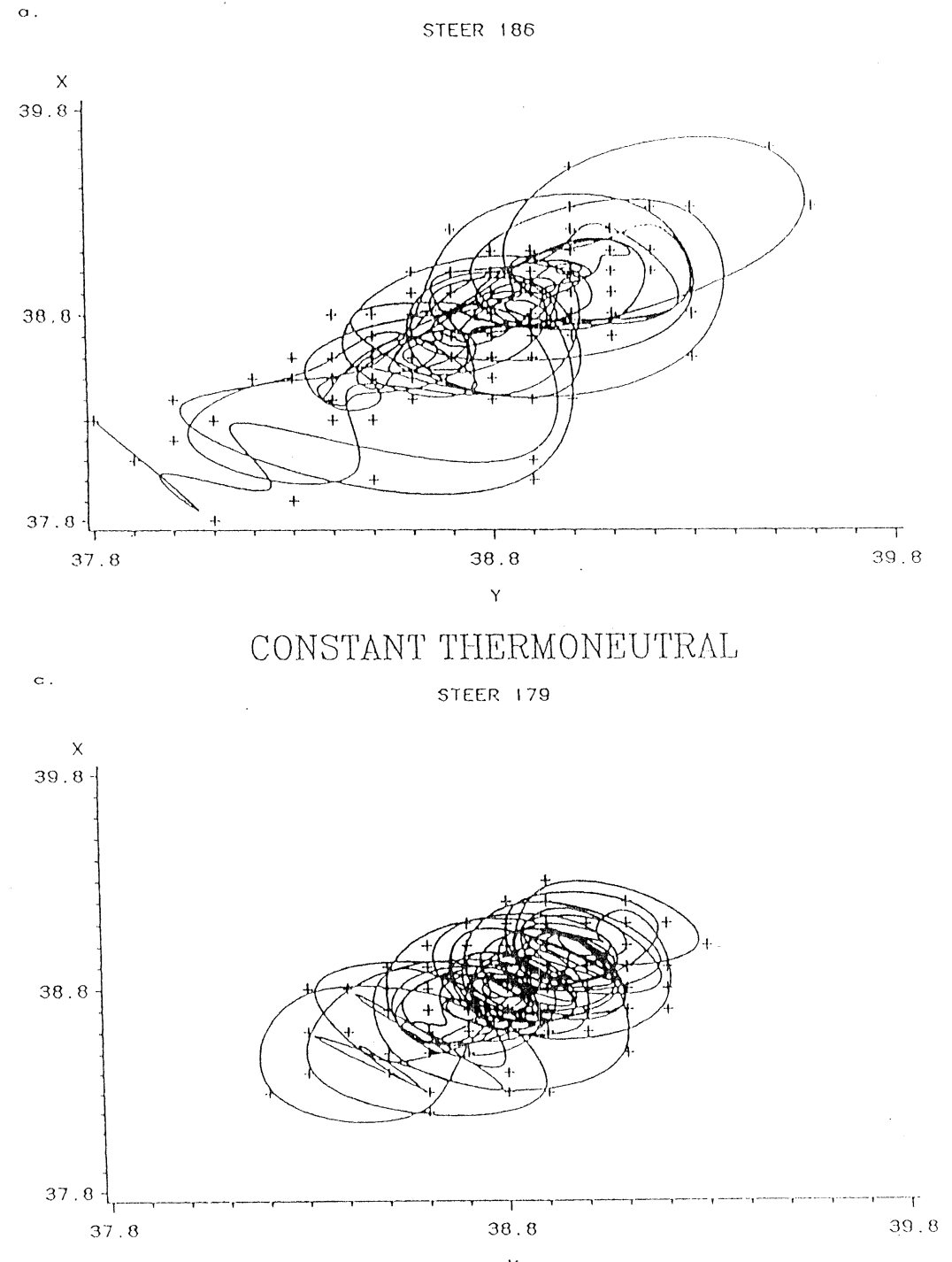

CYCIIC THERMAL STRESS STEER 1 Bo

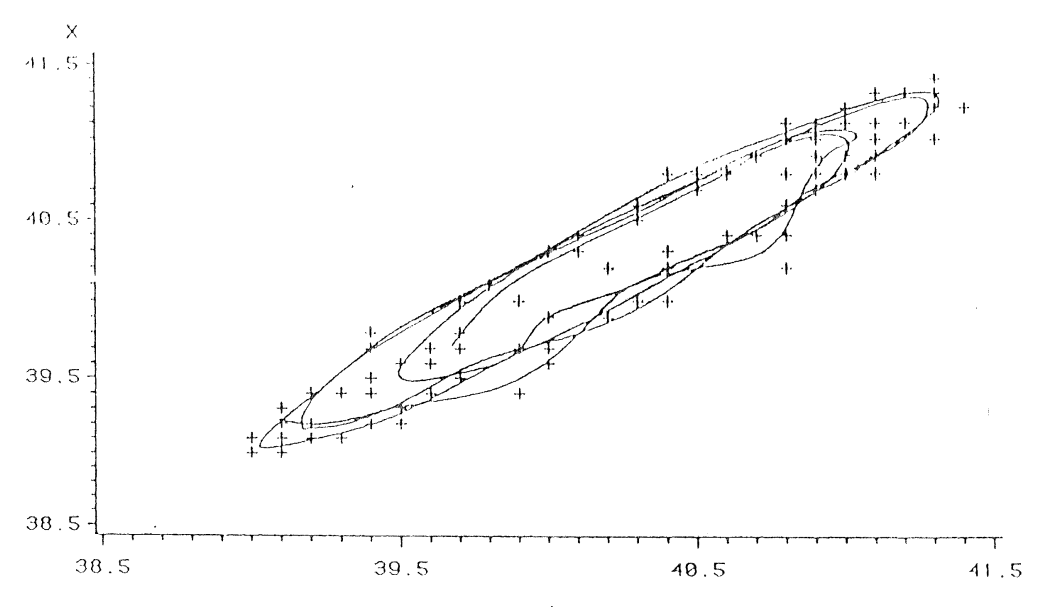

CONSTANT THERMAL STRESS

STEER 179

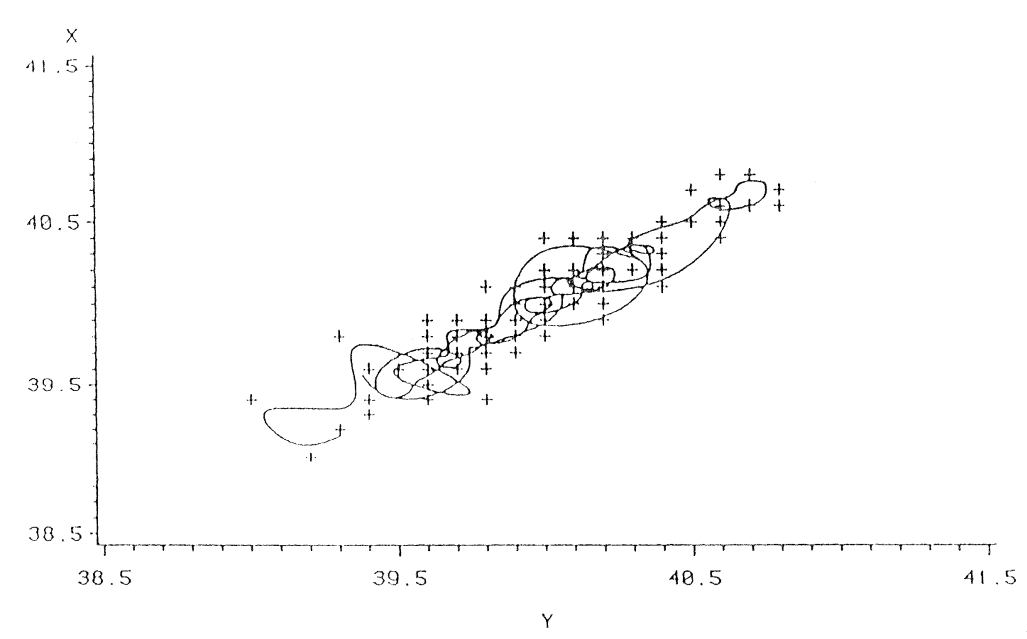


Figure 4. Spectral Analysis

\section{for Tympanic Temperature}

CYCLIC THERMONEUTRAI

SPECTRAL ANALYSIS
STEER 186

CYCLIC THERMAL STRESS

SPECTRAL ANALYSIS
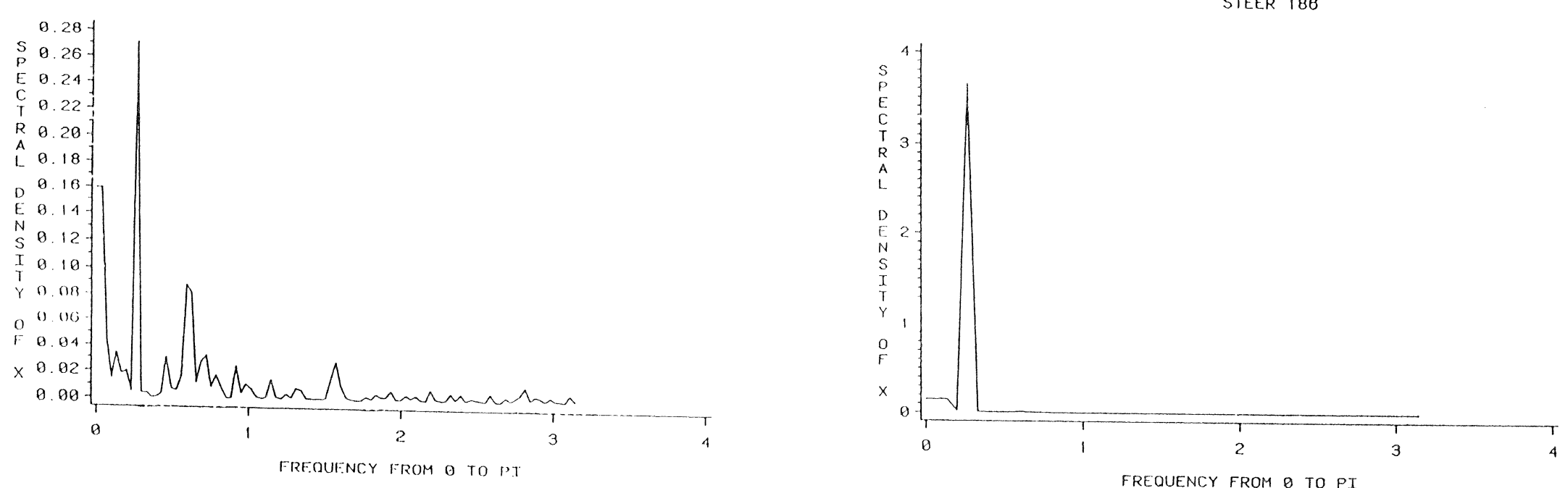

CONSTANT THERMONEUTRAI

SPECTRAL ANALYSIS
STEER 179

CONSTANT THERMAL STRESS

SPECTRAL ANALYSIS
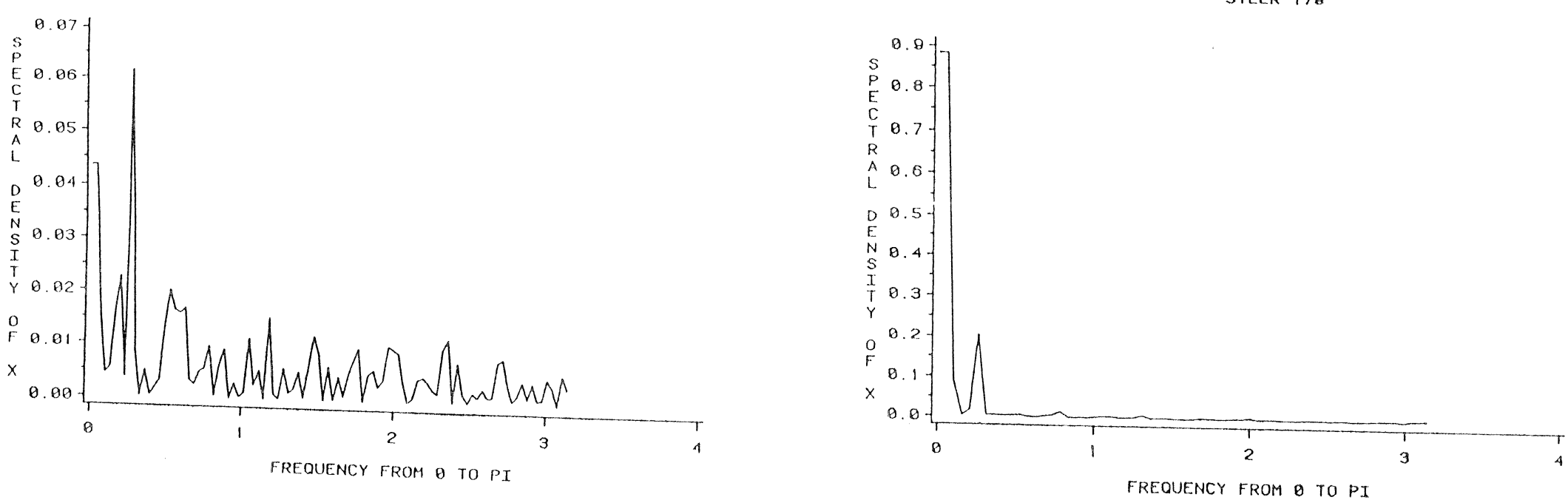